\title{
El laboratori informàtic a l'aula. L'Interactive Physics, fent servir el canó de projecció, una bona eina per ensenyar física
}

\author{
Juli Tena i Frasno \\ Llicència d'estudis modalitat $A$, curs 2008-2009 \\ Jtena2@xtec.cat
}

Les simulacions són un recurs informàtic que ajuda en la tasca docent, però ens trobem amb la dificultat que suposa aplicar una tecnologia amb la que no estem familiaritzats. El que proposo és una metodologia per utilitzar les simulacions IP a l'aula convencional, de manera que no impliqui l'ús d'altres espais.

Paraules clau: Interactive Physics, simulacions, física, projector digital

\section{Introducció}

Dia a dia apareixen en la nostra societat nous recursos informàtics que es poden aplicar en l'aprenentatge de les diferents matèries que impartim a les aules. El Departament d'Educació ha dotat els centres amb programes informàtics, programes que poden ajudar en la tasca docent del professorat.

Això implica que el professorat hauria de trobar prou temps, del qual no sempre disposa, per dedicar-lo a entendre el programa (amb el que no sempre estarà familiaritzat) i preparar el material que li permetrà aplicar aquests recursos a l'aula.

Entre aquests programes informàtics hi ha l'Interactive Physics (IP), que permet dissenyar simulacions del moviment d'objectes sotmesos a les lleis de la mecànica newtoniana (simulacions IP), que ens ajuden a entendre la Física. Però l'ús que se'n fa actualment, tant per part del professorat com de l'alumnat, no sol aprofitar totes les possibilitats d'aquesta eina.

\section{Objectiu}

La idea de partida és la següent: "si donem a conèixer a l'alumnat i al professorat les possibilitats de treball que ens proporcionen les simulacions per a l'estudi de diferents moviments, i una metodologia adequada per treballar-les, canviarà l'actitud que professorat i alumnat tenen en relació a l'ús de les simulacions en el procés d'ensenyament-aprenentatge de la Física?"

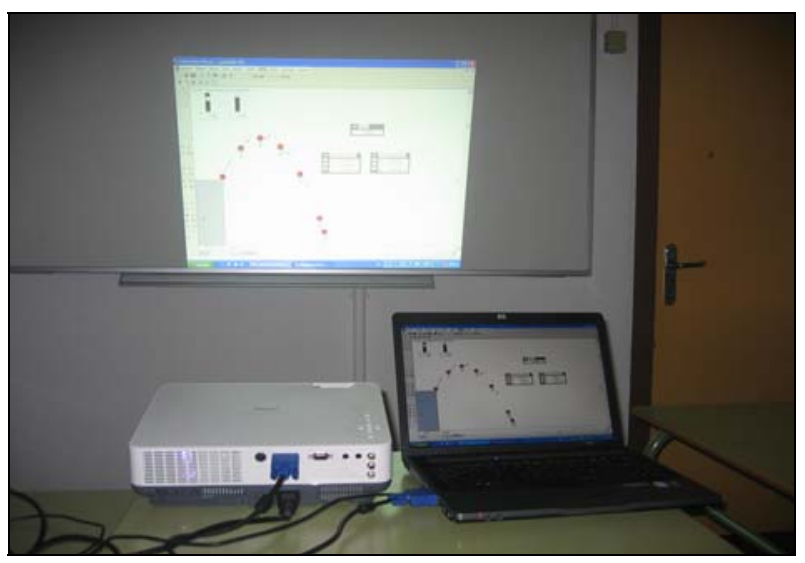

Podem suposar que l'ús de les simulacions, utilitzant una metodologia adequada, ajudarà el professorat i l'alumnat en el procés d'ensenyamentaprenentatge de la física.

En aquesta recerca he estudiat la viabilitat de fer servir les simulacions amb l'Interactive Physics, amb el suport del canó de projecció, com a eina per explicar els continguts del currículum de física de Batxillerat.

El lloc de treball és directament l'aula convencional, amb tot el grup-classe. D'aquesta manera s'evita l'ús d'espais especials (com ara l'aula d'informàtica) normalment molt sol-licitats i d'escassa disponibilitat. 
El que pretenc és proposar canvis en la manera com el professorat utilitza les simulacions i d'aquesta forma incrementar el seu ús a classe.

\section{Metodologia utilitzada}

La recerca l'he realitzada amb l'alumnat i el professorat de set grups diferents de sis centres públics d'ensenyament secundari i hi han col-laborat 96 alumnes de física de $1 \mathrm{r}$ de Batxillerat i 12 professors i professores.

Cada grup ha participat en unes sessions en les que s'hi han realitzat les activitats amb l'ús de les simulacions i s'hi han contestat els qüestionaris que m'han permès la recollida de les dades que he utilitzat per fer la recerca. Aquestes sessions les he realitzades durant els mesos de gener i febrer del 2009, moment que es corresponia amb la temporització de la matèria que s'hi han aplicat les activitats.

Durant el primer trimestre del curs 2008-2009 he preparat el material necessari per realitzar les activitats a l'aula. Aquestes activitats es basaven en l'estudi de tres tipus de moviments d'un objecte i es realitzaren al llarg de quatre sessions.

Per a l'estudi de cadascun dels tres moviments he elaborat:

- Un dossier d'activitats per a l'alumnat (fig. 1).

- Les simulacions realitzades amb l'Interactive Physics, que permeten representar els moviments que volem estudiar (fig. 2).

- El Powerpoint que facilita al professorat la correcció de les activitats en el moment d'aplicarles a l'aula per a tot el grup classe (fig. 3).

També he elaborat els qüestionaris per al professorat i per a l'alumnat, que són els que em proporcionaran les dades necessàries per analitzar si s'ha produït un canvi d'actitud en relació a l'ús de les simulacions després de realitzar les activitats.

En les dates acordades amb el professorat dels diferents centres he realitzat sis sessions a cadascun dels grups participants en l'estudi. Hi han estat presents tant l'alumnat com el professorat del grup.

La primera sessió, prèvia a la realització de les activitats amb el suport de les simulacions, vaig passar un qüestionari al professorat i a l'alumnat per obtenir les dades que em permeteren conèixer l'opinió que tenien envers les simulacions i l'ús que en fan.

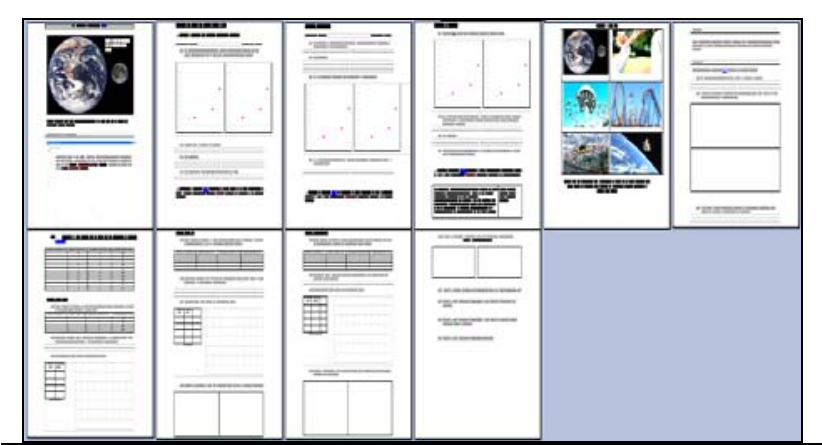

Figura 1. Dossier d'activitats per a l'alumnat.

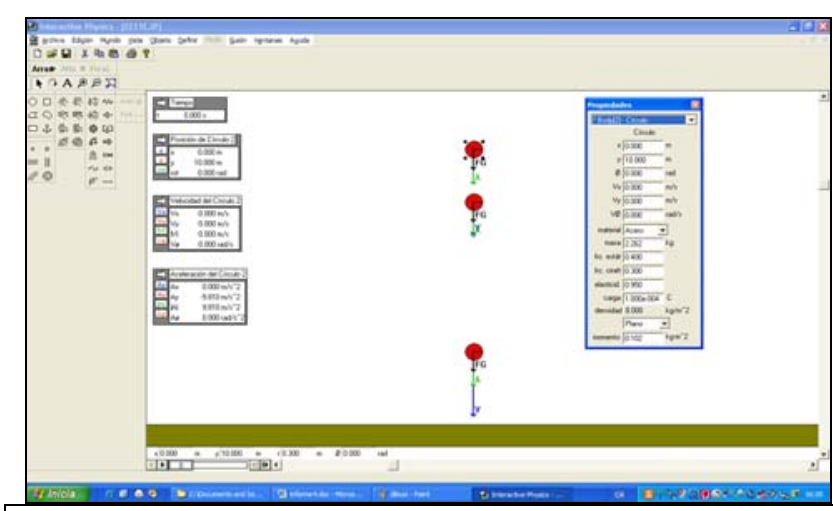

Figura 2. Una de les simulacions amb Interactive Physics.
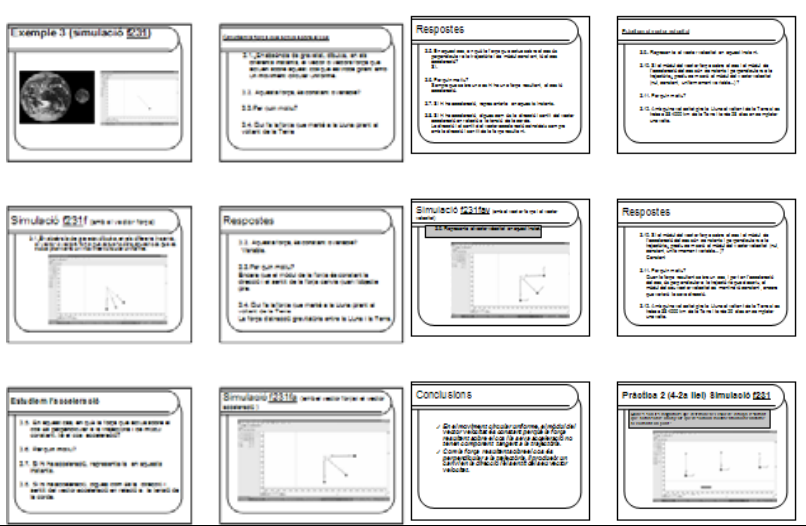

Figura 3. Un dels Powerpoints preparats.

Les quatre sessions següents vaig realitzar les activitats amb l'alumnat, en presència del professorat, donant a conèixer les diferents possibilitats de treball que ens ofereixen les simulacions. L'equipament utilitzat per realitzar aquestes activitats es va reduir a un ordinador i un canó de projecció portàtils amb els quals projectava les simulacions IP i els PowerPoints. 
La sisena i darrera sessió el professorat i l'alumnat van contestar un qüestionari que em va permetre conèixer la seva opinió sobre la metodologia seguida i sobre l'ús que havíem fet de les simulacions en les activitats realitzades.

\section{Resultats}

Els resultats de l'enquesta prèvia mostren que només una petita part del professorat i de l'alumnat (al voltant del 10\%) utilitza freqüentment les simulacions com a eina per a l'estudi de la física.

Les simulacions que usen ja estan prèviament dissenyades i es treballen com a activitats ailllades en determinades aules on hi ha l'equipament que necessiten. En cap cas s'utilitzen les simulacions com una eina més per entendre els conceptes de física dins de l'aula del grup-classe.

Els motius més importants perquè el professorat no les utilitzi són:

- No està familiaritzat amb els programes

- No disposa de temps per preparar les activitats amb l'ús de les simulacions

- No disposa de temps per treballar aquestes activitats a classe

- No troba simulacions que s'adeqüin a la matèria

- No disposa de l'espai físic ni de l'equipament adequat en el moment que ho necessita

El fet que el professorat no dissenyi les seves pròpies simulacions, la falta de disponibilitat d'aules amb la dotació i el programari necessaris i el fet de no poder realitzar aquestes activitats dins de l'aula que normalment té assignada, fan que la utilització de les simulacions per part del professorat i de l'alumnat com a eina per a l'ensenyament i l'aprenentatge de la física sigui escassa o nul-la.

\section{Conclusions i implicacions}

Per solucionar o minimitzar aquestes dificultats he proposat, dins de les activitats realitzades amb l'alumnat i el professorat, una metodologia de treball:

- En primer lloc el professorat, i si és possible també l'alumnat, ha d'estar familiaritzat amb el programa de simulacions que s'utilitza i conèixer tant les tècniques de disseny i manipulació del programa com les múltiples possibilitats que ens ofereix.

- Al principi les simulacions que dissenyi el professorat han de ser el més senzilles possible i adaptades als objectius que pretén assolir en cada moment. De les opcions que ens ofereixen les simulacions (observar la trajectòria, visualitzar determinats vectors, obtenció de dades, confeccionar gràfics, passar les imatges a poc a poc, aturar-les...), les que utilitzarem dependran de les necessitats que se'ns plantegin a cada moment en les activitats que voldrem realitzar.

- Quan planifiquem les activitats, aquestes poden ser bàsicament de dos tipus: qüestions curtes i de tractament de dades. En les qüestions curtes l'alumnat fa prediccions que posteriorment discuteix i corregeix amb l'ajut de les simulacions, si cal. El tractament de les dades ens permetrà deduir o comprovar les lleis de la física.

- La dotació que hem utilitzat es limita a un canó de projecció portàtil i un ordinador també portàtil i ha permès realitzar les activitats amb l'alumnat a l'aula que el grup té assignada, encara que no disposi de cap tipus d'equipament. D'aquesta forma podem projectar les simulacions i els PPT en una pantalla (o sobre la pissarra o la paret).

El fet d'utilitzar el nostre propi ordinador portàtil ens dóna els següents avantatges:

- Ens resulta més fàcil disposar dels programes que necessitem per realitzar les activitats.

- Ens fa el paper de taula de laboratori on podrem preparar, en qualsevol lloc i moment, simulacions, qüestionaris i PPT que posteriorment utilitzarem en les activitats a realitzar amb l'alumnat.

- Podem preparar i controlar millor el material necessari per a cada sessió.

Amb aquest equipament podem utilitzar les simulacions com una eina més, en qualsevol moment, fins i tot de forma puntual, dins de l'aula que té assignada el grup classe, sense necessitat de desplaçar-nos amb l'alumnat ni de sol-licitar prèviament l'ús de cap aula especial.

La projecció de les simulacions a la pantalla permet centrar l'atenció de tot el grup classe en una mateixa activitat i ajuda l'alumnat a entendre els conceptes i a corregir les qüestions plantejades.

En conjunt, les activitats realitzades utilitzant les simulacions projectades amb el canó de projecció ajuden a arribar a conclusions o a comprovar lleis de la física que d'altra forma s'haurien de fer de manera totalment teòrica o que simplement no es poden comprovar al laboratori.

Les dades que ens ha proporcionat el qüestionari realitzat tant al professorat com a l'alumnat després de fer les activitats a l'aula, ens donen uns resultats totalment diferents als de l'enquesta prè- 
via. La totalitat del professorat (100\%) i la major part de l'alumnat (més del $80 \%$ ) són favorables a l'ús de les simulacions per explicar la física.

Amb aquestes dades podem concloure que si el professorat i l'alumnat coneixen les possibilitats que els ofereixen les simulacions i una metodologia que els faciliti treballar-les a l'aula, les simulacions són una bona eina per a l'ensenyament i aprenentatge de la física.

\section{Bibliografia}

CASELLAS I GISBERT, O. (2005). Laboratori Virtual de física. Llicència retribuïda 2004-2005. Departament d'Educació. Generalitat de Catalunya.

FERNANDEZ, C. ORO, J. I PLANA, O. Materials de Formació del professorat. Simulacions amb Interactive Physics. Departament d'Educació. Generalitat de Catalunya.

FERRER GUARNER, J. M. Simulacions per ordinador: Una eina per innovar la didàctica de la física.
FONTANET. A. (2006). Presentació de problemes de física amb Interactive Physics. Llicència retribuïda 2005-2006. Departament d'Educació. Generalitat de Catalunya.

GUITART, F. (2005). Recursos $i$ activitats a Internet: Ús eficaç dels recursos $i$ activitats a Internet per a l'ensenyament de les ciències a l'ESO. Llicència retribuïda 2004-2005. Departament d'Educació. Generalitat de Catalunya.

INTERACTIVE PHYSICS (2000). Manual de usuario. MSC. Software. Redwood. City. California.

ORO SANCHO, J. Integració de l'ús de tecnologies de la informació per l'ensenyament de la física al Batxillerat.

PERALES, F. J. I SIERRA, J. L. Los trabajos de investigación en el aula de física con simuladores informáticos: Interactive Physics Versus Mobile.

ROJANO, T. (2003). Incorporación de entornos de aprendizaje a la cultura escolar: proyecto de innovación educativa en matemáticas y ciencias en escuelas secundarias públicas de México. Revista Ibero-Americana.

THORNTON, R.K. Aprenentatge interactiu en classes grans $i$ petites utilitzant sensors, ILDs (Interactive Lecture Demostracions). 